THURSDAY, SEPTEMBER 10, I885

\section{OUR PRESENT NEEDS}

IF $F$ it be fair to forecast the success of a meeting of the British Association by the quality of the addresses delivered by the various presidents, then we may predict that the meeting of this year at Aberdeen, which began yesterday, will stand out among its fellows. We think it would be hard to find any prior occasion on which such a high standard of excellence had been reached all round.

The growing use as well as the growing feeling for the need of scientific methods comes out in a most unmistakable way, while there is no fear that either hearers or readers will be lulled into a Sleepy Hollow of satisfaction or a rest-and-be-thankful feeling. For that much remains to be done even in the way of initial organisation both of teaching and working, is frankly and fearlessly acknowledged by several of the speakers.

These present needs may well occupy our attention, and we may begin by those pointed out by the President of the Association himself, who speaks both as a man of Science and a politician. No one knows better than Sir Lyon Playfair how Science can aid the body politic, or knows better how each party when in office neglects or uses this powerful engine for the nation's good. $\mathrm{He}$ begins by quoting these noble words from the address of the President at the Aberdeen Meeting in 1859-the lamented Prince Consort:-_"We may be justified in hoping ... that the Legislature and the State will more and more recognise the claims of Science to their attention, so that it may no longer require the begging box, but speak to the State like a favoured child to its parent, sure of his paternal solicitude for its welfare; that the State will recognise in Science one of its elements of strength and prosperity, to foster which the clearest dictates of self-interest demand."

One can get no better idea of the Philistine condition of the Government and of the House of Commons in matters of science than from the fact that much of what follows in the President's Address has not been said in the House itself instead of at Aberdeen. The real reason perhaps is to be gathered from a remark made by Prof. Chrystal in his address in Section A :-

"We all have a great respect for the integrity of our British legislators, whatever doubts may haunt us occasionally as to their capacity in practical affairs. The ignorance of many of them regarding some of the most elementary facts that bear on every-day life is very surprising. Scientifically speaking, uneducated themselves, they seem to think that they will catch the echo of a fact or the solution of an arithmetical problem by putting their ears to the sounding-shell of uneducated public opinion. When I observe the process which many such people employ for arriving at what they consider truth, I often think of a story I once heard of an eccentric German student of chemistry. This gentleman was idle, but, like all his nation, systematic. When he had a precipitate to weigh, instead of resorting to his balance, he would go the round of the laboratory, hold up the test-tube before each of his fellow-students in turn, and ask him VOL. XXXII.-No. 828 to guess the weight. He set down all the replies, took the average, and entered the result in his analysis."

Now if this view of our legislators is shared by men of such acumen as Sir Lyon Playfair and others in the House of Commons more or less connected with science, we can well understand their silence in the modern council of the nation which so little resembles the Witanagemote of former times.

In his pleading for more State recognition of science the President points out the present activity of Germany and France, and especially of the United States:

". . . Both France and Germany make energetic efforts to advance Science with the aid of their national resources. More remarkable is it to see a young nation like the United States reserving 150,000,000 acres of national lands for the promotion of scientific education. In some respects this young country is in advance of all European nations in joining Science to its administrative offices. Its scientific publications, like the great palæontological work embodying the researches of Prof. Marsh and his associates in the Geological Survey, are an example to other Governments. The Minister of Agriculture is surrounded with a staff of botanists and chemists. The Home Secretary is aided by a special Scientific Commission to investigate the habits, migrations, and food of fishes, and the latter has at its disposal two specially constructed steamers of large tonnage. The United States and Great Britain promote fisheries on distinct systems. In this country we are perpetually issuing expensive Commissions to visit the coasts in order to ascertain the experiences of fishermen. I have acted as Chairman of one of these Royal Commissions, and found that the fishermen, having only a knowledge of a small area, gave the most contradictory and unsatisfactory evidence. In America the questions are put to Nature, and not to fishermen. Exact and searching investigations are made into the life-history of the fishes, into the temperature of the sea in which they live and spawn, into the nature of their food, and into the habits of their natural enemies. For this purpose the Government give the cooperation of the Navy, and provide the Commission with a special corps of skilled naturalists, some of whom go out with the steamships, and others work in the biological laboratories at Wood's Holl, Massachusetts, or at Washington. . . . The practical results flowing from these scientific investigations have been important. The inland waters and rivers have been stocked with fish of the best and most suitable kinds. Even the great ocean which washes the coasts of the United States is beginning to be affected by the knowledge thus acquired, and a sensible result is already produced upon the most important of its fisheries. The United Kingdom largely depends upon its fisheries, but as yet our own Government have scarcely realised the value of such scientific investigations as those pursued with success by the United States."

He quotes with approval a passage from Washington's farewell to his countrymen: "Promote as an object of primary importance institutions for the general diffusion of knowledge. In proportion as the structure of a Government gives force to public opinion it is essential that public opinion should be enlightened." He next points 
out that it was not till 1870 that England established a system of education at all, and that now, while all great countries, except our own, have Ministers of Education, we have only Ministers who are managers of primary schools.

Passing on to the State need of abstract knowledge, we read as follows :--

"Ali, the son-in-law of Mahomet, the fourth successor to the Caliphate, urged upon his followers that men of science and their disciples give security to human progress. Ali loved to say, 'Eminence in science is the highest of honours ;' and 'He dies not who gives life to learning.' In addressing you upon texts such as these my purpose was to show how unwise it is for England to lag in the onward march of science when most other European Powers are using the resources of their States to promote higher education and to advance the boundaries of knowledgc. English Governments alone fail to grasp the fact that the competition of the world has become a competition in intellect."

We have seen how Sir Lyon Playfair twits the heads of the Education Department with being merely managers of primary schools. The Prosident of the Chemical Section, Prof. Armstrong, also shows reason why their functions must be expanded if science is ever to get on here. He holds that without State action the difficulties which at present prevent the existing teaching institutions from exercising their full share of influence upon the advancement of our national prosperity are all but insuperable. He foresees the objection that such an interference would deprive teaching-centres of their individuality, but he denies that this must necessarily follow, and we know no one who has a better right to express an opinion on such a subject.

Some part indeed of Prof. Armstrong s address is terrible reading. The present chemical education and chemical examinations in this country arc, according to him, to a large extent shams, and worse. The students who come to the centres of higher instruction are scarcely reasoning beings - they have never been brought to reason; and at those centres the instruction has been of too technical a character, while hardly anywhere is there an atmosphere of research. We commend this part of Prof. Armstrong's address strongly to our readers. $\mathrm{He}$ points out, among many other matters, the vital importance of the research atmosphere, and he frankly states the difficulties felt by earnest men. On this point, indeed, we think him a little too sensitive. Many of the remarks so often made now touching the absence of research in our chemical laboratories apply not to such men as him, but to those whose trading spirit and proclivities are well known-men who discredit the profession to which they belong. Still, it is well that the difficulties should be fairly recorded, especially in juxtaposition with a statement that absence of research must always indicate the absence of teaching worthy of the name.

A complete revision of the present system, both of teaching and examining in chemistry, is, therefore, according to Prof. Armstrong, one of the most pressing of our present needs.

Are the other sciences better off? Certainly not mathematics if Prof. Chrystal has a right to speak for that branch:
"All men practically engaged in teaching who have learned enough, in spite of the defects of their own early training, to enable them to take a broad view of the matter, are agreed as to the canker which turns everything that is good in our educational practice to evil. It is the absurd prominence of written competitive examinations that works all this mischief."

But some may think that in the setting of problems mathematics teachers have an advantage over others in preventing unintelligent cramming. This is not Prof. Chrystal's opinion :

"The history of this matter of problems, as they are called, illustrates in a singularly instructive way the weak point of our English system of education. They originated, I fancy, in the Cambridgc Mathematical Tripos Examination, as a reaction against the abuses of cramming bookwork, and they have spread into almost every branch of science teaching-witness test-tubing in chemistry. At first they may have been a good thing; at all events the tradition at Cambridge was strong in my day, that he that could work the most problems in three or two and a half hours was the ablest man, and, be he cver 50 ignorant of his subject in its width and breadth, could afford to despise those less gifted with this particular kind of superficial sharpness. But, in the end, came all to the same : we were prepared for problem-working in exactly the same way as for bookwork. We were directed to work through old problem papers, and study the style and peculiarities of the day and of the examiner. The day and the examiner had, in truth, much to do with it, and fasbion reigned in problems as in everything else. The only difference I could ever see between problems and bookwork was the greater predominance of the inspiriting element of luck in the former; This advantage was more than compensated for by the peculiarly disjointed and, from a truly scientific point of view, worthless nature of the training which was employed to cultivate this species of mental athletics. The result, so far as problems worked in examinations go, is, after all, very miserable, as the reiterated complaints of examiners show; the effect on the examinee is a well-known encrvation of mind, an almost incurable superficiality, which might be called Problematic Paralysis--a disease which unfits a man to follow an argument cxtending beyond the length of a printed octavo page."

As to the crying present need, Profs. Chrystal and Armstrong are at one. We want a higher ideal of education in general and of scientific education in particular :

"Science cannot live among the people, and scientific education cannot be more than a wordy rehearsal of clead text-books, unless we have living contact with the working minds of living men. It takes the hand of God to make a great mind, but contact with a great mind will make a little mind greater. The most valuable instruction in any art or science is to sit at the feet of a master, and the next best to have contact with another who has himself been so instructed. No agency that I have ever seen at work can compare for efficiency with an intelligent teacher, who has thoroughly made his subject his own. It is by providing such, and not by sowing the dragon's, teeth of cxaminations, that we can hope to raise up an intelligent gencration of scientifically educated men, who shall help our race to keep its place in the struggle of 
nations. In the future we must look more to men and to ideas, and trust less to mere systems. Systems have had their trial. In particular, systems of examination have been tested and found wanting in nearly every civilised country on the face of the earth."

What we have written will show what food for thought in the matter of our present needs has been provided at Aberdeen for those gathered together for the advancement of science. Surely the three addresses to which we have specially referred in the present article suggest a gap in the organisation of the Association. Why should there not be a section to deal specially with the question of Education and Research?

\section{THE "DECOMPOSITION" OF DID YMIUM}

U DER the above title the Chemical News has recently reprinted from the Chemiker Zeitung a notice of an important piece of work recently communicated to the Vienna Academy by Dr. C. A. von Welsbach. The work appears to have resulted in the discovery that the "dyad or triad element" didymium with an "atomic weight" of 48 or 96 , or 147 , according to the text-books employed, and which since its separation by Mosander in 1841 has been investigated by Marignac, Hermann, Watts, Bunsen, Deville, and Erk, not to mention many others, is no element at all, but is built up of two substances which can be separated from each other by an ordinary chemical process. The "decomposition" was in fact effected by means of the double ammonium or sodium nitrates in presence of lanthanum salt.

The colours of the salts of the two substances are quite different. The salts of that which approaches lanthanum in its chemical characteristics are of a leek-green, those of the other substance are rose or amethyst red, and it is this substance which exists in greatest quantity in didymium. Dr. von Welsbach proposes for these two new substances the names of "praseodymium" and "neodymium."

It will be readily seen that from the chemical point of view alone these results are of very high interest, but there is another from which they assume a very great importance.

The "element" didymium after it was separated by the chemist had been handed over to the physicists. Gladstone, we believe, was among the first to note the characteristic absorption spectrum of the salts. In this work he was followed by Bahr and Bunsen, Erk and others. Thalèn determined its spark spectrum, and in our spectroscopic literature didymium has taken its place by the side of hydrogen and iron as a characteristic spectrum-giving element.

Now one of the arguments which has been used in support of the view put forward some time ago of the dissociation of the chemical elements at solar temperatures is that at one "heat level" in the sun's atmosphere (a term coined because the sun's atmosphere must get hotter as we go down, and we have means of determining which vapours ascend from hotter regions and which descend from cooler ones) we get some lines of the spectrum of a substance, let us say iron, and at another we get others ; so that to get the complete spectrum of iron, as we see it when we use iron in our laboratories, we have to add together the two sets of lines seen in the spectra of parts of the sun known to be at different temperatures.

To make our statements more precise we may say that the lines of iron seen bright in the spectra of solar prominences and those seen widened in the spectra of solar spots are so different that it may be said that there is hardly a line common to both. So much so that, as was said years ago, if we did not know iron here, and the fact that its spectrum contains both sets of lines, we should say that the prominences quat iron contained one substance, and the spots quâ iron contained another.

These facts were explained by the hypothesis that there were in the so-called element iron at least two different substances or molecular groupings, one of which alone could withstand the higher temperature of the prominences. The reason that both sets of lines and many others are seen in the spectrum of iron in the hightension spark is that the temperature of the spark is sufficient to carry the solid metal through the series of simplifications, whether many or few, which lie between the limits formed by the solid state and the temperature of the prominences.

To this it has been objected that if these things exist in iron they should be isolated and put in bottles. To this it has been replied that the bottles themselves must be incandescent, or the "things" will unite again as they have done before to form iron as we know it.

Now the real importance of Dr. von. Welsbach's work is that what has not yet been done for iron-to prove beyond all cavil the above hypothesis-he has done for didymium. He has got into two bottles, which we may mentally label "spot bottle," "prominence bottle," two substances from the "element" didymium, each of which has a characteristic spectrum consisting of different parts of the spectrum of didymium just as the spots and prominences have spectra quâ iron, which are different parts of the spectrum of iron. Further, by mixing the substances in these two bottles together in proper proportions he can produce a third, which gives the mapped spectrum of didymium exactly as in the general spectrum of the sun, in which we get, added together, the absorptions of the hotter and cooler regions represented by prominences and spots, we have $q u \dot{a}$ iron, something not unlike the arc spectrum of that substance.

There is no doubt that the interest of both chemists and physicists will be keenly excited by Von Welsbach's work, and that it will be critically examined and repeated. If it be confirmed we may hope that some day similar work will be undertaken here. The way is open, and has been cleared in a remarkable way. Formerly it was imagined that very high temperatures and new chemical methods were the sole agents to which appeal could be made in such a case; it may turn out that there are reagents to hand if chemists will turn their attention to them.

It is further clear that the "elements" with high atomic weight should be the first to be attacked. Those who consider the spectrum of cerium, for instance, which in the blue and violet portion is richer in lines than the spectrum of the sun itself, to be produced by the vibration of "the chemical atom" or " the chemical molecule," no matter which, will find themselves in a hopeless minority, now that the simpler explanation of a mixed 